\title{
Genealogias entre as imagens da Língua Apunhalada de Lygia Pape e uma cena do filme Família do Barulho de Julio Bressane
}

\author{
Mario Caillaux ${ }^{1}$
}

Resumo: Este artigo tem como objetivo principal analisar as semelhanças e os pontos de contato que as artes plásticas, no período de 1960 e 1970, tiveram com o cinema, mais especificamente o movimento do cinema marginal. Para isso, iremos analisar duas imagens: o trabalho Língua Apunhalada, de Lygia Pape, e uma das cenas finais do filme Família do Barulho, de Julio Bressane, em que a atriz Helena Ignez vomita sangue, para tentar encontrar uma genealogia que as ligue. Buscaremos entender até que ponto as semelhanças vão além dessas coincidências e até que ponto essas línguas falam o mesmo idioma, apenas com sotaques diferentes. No caso, esse acento diferenciado seriam os seus meios, os circuitos. Palavras-chave: Língua Apunhalada; Lygia Pape; Família do Barulho; Helena Ignez; experimentalismo

\section{Genealogies between the images of Lygia Pape's Língua Apunhalada and a scene from the movie Família do Barulho by Julio Bressane}

\begin{abstract}
This article aims to analyze the similarities and points of contact that the visual arts, in 1960 and 1970, had with the cinema, more specifically the marginal cinema movement. For this, we will analyze two images: the work Língua Apunhalada, by Lygia Pape, and one of the final scenes of Julio Bressane's film Família do Barulho, where the actress Helena Ignez vomits blood, to try to find a genealogy that Turns them on. We will seek to understand to what extent the similarities go beyond these coincidences and to what extent these languages speak the same language with only different accents. In this case, this differentiated accent would be its mediums, the circuits.
\end{abstract}

Keywords: Língua Apunhalada; Lygia Pape; Família do Barulho; Helena Ignez; experimentalism

\footnotetext{
1 Mestre em História da Arte pelo Programa de Pós-graduação em Artes Visuais da UFRJ (PPGAV/UFRJ) com a dissertação Raymundo Colares: além das ultrapassagens. Produtor e montador de cinema, destacando-se os filmes Desarquivando Alice Gonzaga (2017) e Dissecando Antonieta (2015), além de dirigir alguns filmes experimentais como Misterioso Vazio
} 


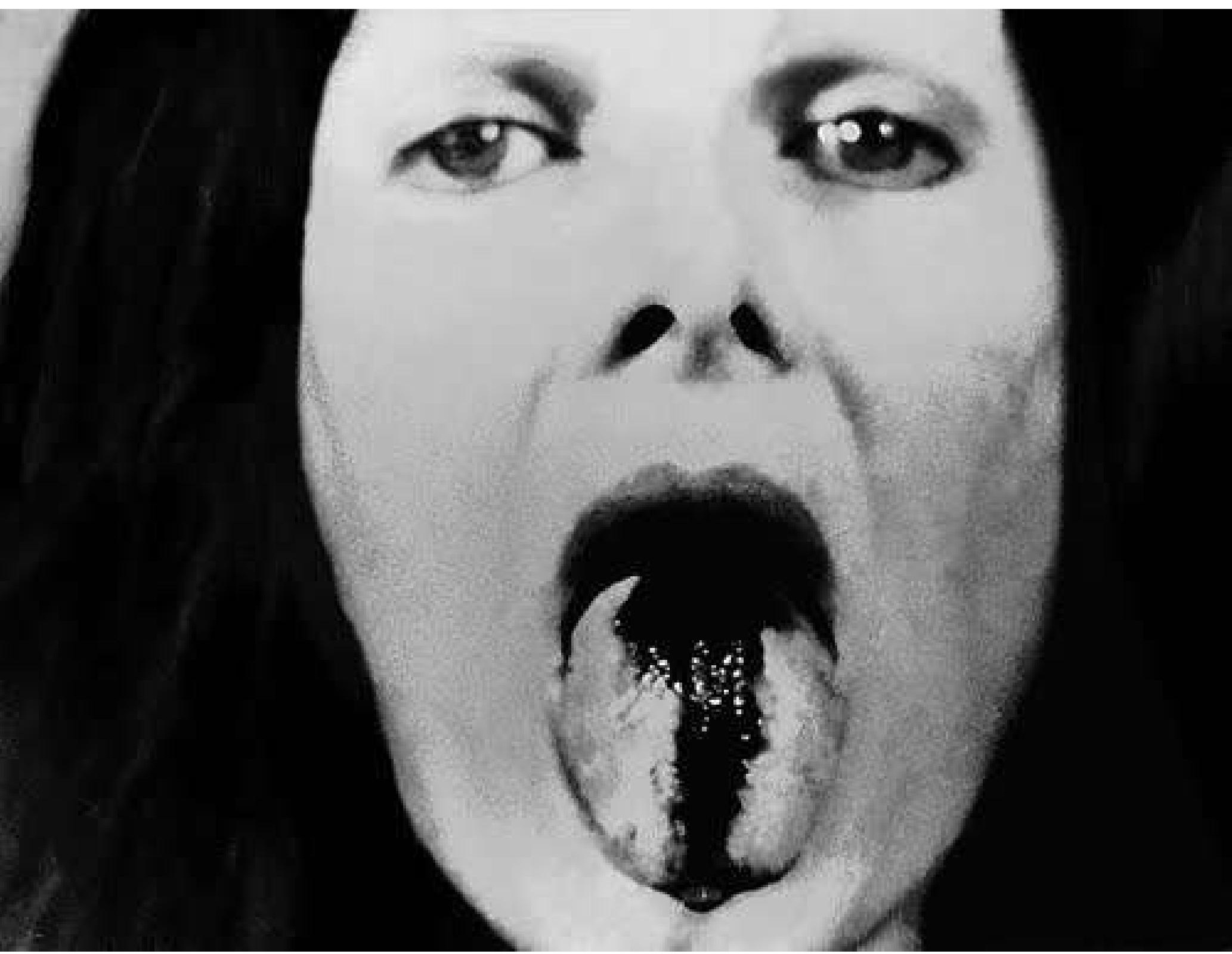

Figura 1

Lygia Pape,

Língua Apunhalada,

1968, fotografia em

preto e branco 


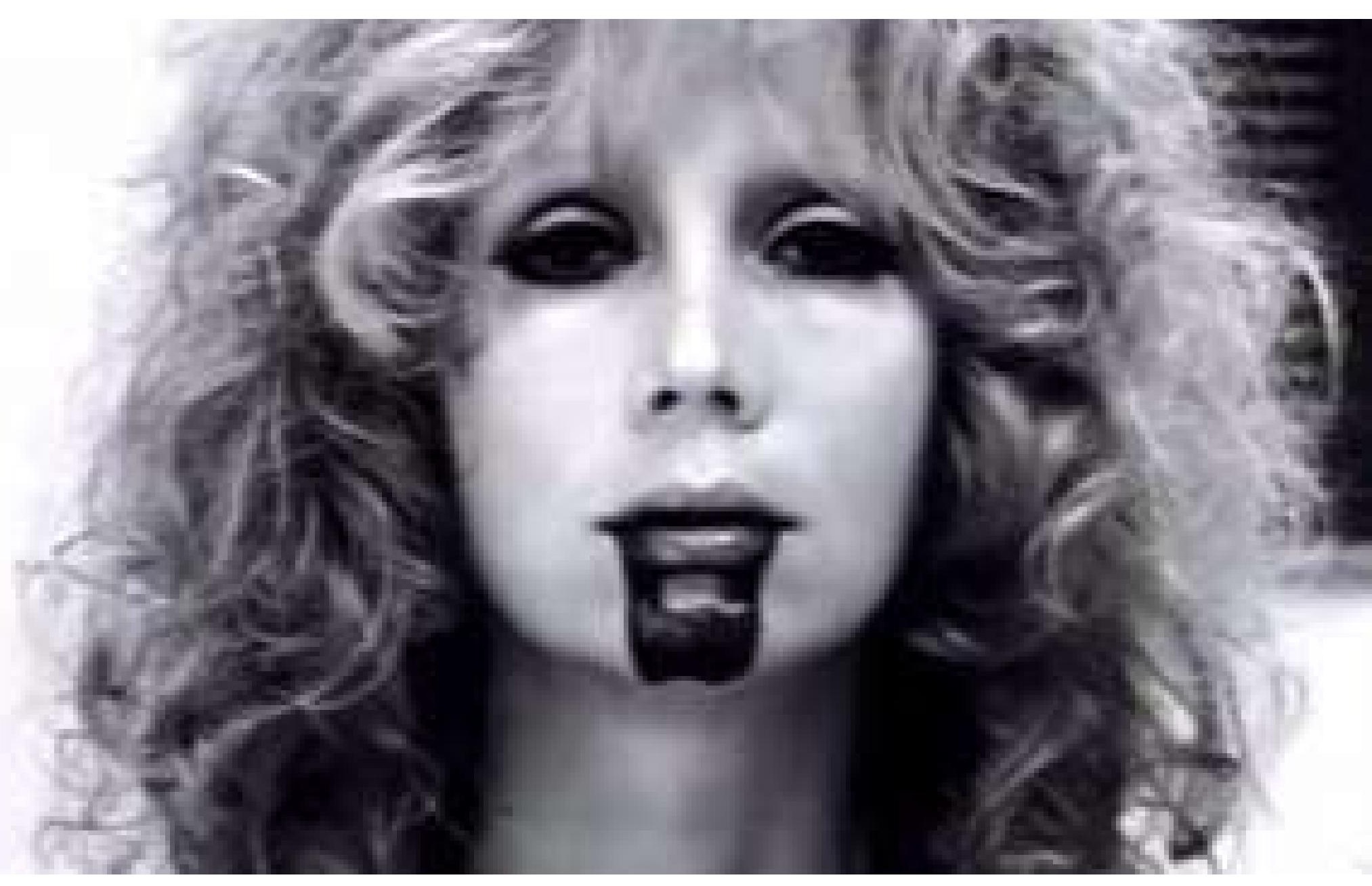

Figura 2

still do filme

Família do Barulho, 1970

de Julio Bressane - A atriz

Helena Ignez vomitando

sangue 


\section{Introdução}

Duas imagens que se tornaram marcantes para exemplificar um determinado período em seus meios no Brasil, nos anos de 1960 e 1970, serão analisadas neste artigo a partir de suas semelhanças. São elas: Língua apunhalada (1968), de Lygia Pape, e uma das cenas finais do filme Família do Barulho (1970), de Julio Bressane, em que a atriz Helena Ignez vomita sangue.

O trabalho de Lygia Pape exemplifica um momento nas artes plásticas brasileiras que foi bastante marcado pelo experimentalismo, com a participação do público e também pela luta pelas liberdades políticas e sociais. Língua apunhalada é um autorretrato fotográfico, em preto e branco, com um close do rosto da artista com a língua para fora. Nessa língua, vemos um líquido preto escorrendo no sentido horizontal, enquanto o título sugere um ato de violência nesse músculo.

Já a imagem da Helena Ignez / Julio Bressane surge numa das cenas finais do filme Família do Barulho. A câmera faz um close do rosto da atriz. Percebe-se um certo incômodo, exemplificado pelos movimentos que a atriz faz em sua garganta. Mais para o final da cena, sem mudança no quadro fotográfico e sem a abrir a boca, um líquido escuro começa a vazar pelas extremidades dos lábios de Helena. Um vômito contido de sangue. Entretanto, a forma que essa mancha adquire no rosto da atriz, um borrão escuro do lábio inferior até o queixo, nos remete a uma língua. Uma língua ensanguentada, como se a atriz estivesse com ela para fora da boca.

Descontextualizando essas duas imagens de seus meios, e olhando-as lado a lado, vemos grandes semelhanças. Apesar da pouca diferença de idade entre uma imagem e outra, apenas dois anos, e dos artistas frequentarem um círculo social comum - a comunidade artística do Rio de Janeiro, que, além das proximidades e afinidades, tinha no MAM o seu ponto de encontro -, não acreditamos que se trate de uma homenagem ou referência, uma vez que nem Pape nem Bressane tiveram contato com essas obras específicas até, no mínimo, o ano de 1971. O filme Família do Barulho, apesar de ser de 1970, teve sua primeira exibição no Rio de Janeiro em fevereiro de 1972, na cinemateca do MAM. Já em relação à foto de Pape, de 1968, não encontramos o registro de quando ela foi apresentada em público pela primeira vez. Todavia, analisando o currículo de exposições da artista, vemos um gesto efêmero, em 1971, chamado de Língua Apunhalada, que aconteceu no ateliê de Vargem Grande, no Rio de Janeiro. Não é possível afirmar, mas, por suposição, tomamos como a primeira apresentação pública desse trabalho. 
O que pretendemos mostrar é que, apesar de partirem de pesquisas estéticas em meios diferentes, existem pontos em comuns na base da construção dessas imagens e, consequentemente, nos trabalhos desses artistas e dos grupos que eles participavam, sendo que a transformação da obra de arte, o alargamento de suas fronteiras, era compartilhada tanto pelas artes plásticas quanto pelo próprio cinema. Uma transformação da própria linguagem e do objeto artístico, fossem eles fotografia, pintura, filme ou objeto. Porém, nesses dois casos, toda essa transformação aconteceu seguindo preceitos bem próximos, como a incorporação de um tipo de experimentalismo.

A questão temática sem dúvida se sobressai, principalmente se levarmos em conta o momento político que o Brasil vivia. Diversas análises e estudos de ambos os trabalhos percorreram esse caminho, apontandoos como uma estratégia de resposta à conturbada situação política ou, ainda, de introdução de novos temas - questões sociais e de gênero que, até então eram, de certa maneira, ignoradas por nossa cultura.

É um fato a ser registrado que esses artistas sofreram na pele a violência do Estado no regime ditatorial. Bressane, junto a Rogério Sganzerla e Helena Ignez, saíram do país no ano de 1970, após um aviso de que seus filmes estavam sendo considerados subversivos. Já Lygia Pape, no ano de 1973, foi presa na base aérea do Galeão no Rio de Janeiro. ${ }^{2}$

Todavia, sem ignorar as questões políticas e sociais que influenciaram na temática dos trabalhos, acreditamos se tratar mais de uma consequência do que a causa principal na criação dessas obras. Como nos lembra Marie-José Mondzain, analisando a questão da imagem no cinema:

Haverá talvez duas figuras do invisível no visível dos ecrãs: aquela que assume a encarnação e aquela que só se preocupa com a incorporação. O lugar atribuído ao espectador é em cada caso essencialmente diferente. E no trabalho da própria

\footnotetext{
2 Sobre a prisão de Pape, em palestra que ocorreu no Parque Lage do Rio de Janeiro, no ano de 2008, os artistas Antonio Manuel e Carlos Zilio, junto com os críticos Glória Ferreira e Paulo Sergio Duarte, discutiram a relação da ditadura nas artes plásticas. Essa palestra foi gravada pela artista e professora Simone Michelin e, no ano de 2018, foi apresentada na exposição Al-5 50 anos - Ainda não terminou de acabar, com curadoria de Paulo Miyada, no Instituto Tomie Ohtake, em São Paulo. Em relação a Julio Bressane: depoimento do cineasta no filme Belair (2009), de Noa Bressane e Bruno Safadi.
} 
imagem que se joga este intervalo irredutível e não no conteúdo ideológico explícito da narrativa. (Mondzain, 2009 p.63)

A força da imagem é constituída por ela própria, sem necessariamente ter o auxílio da narrativa. E é justamente essa potência autônoma, que essas duas imagens nos trazem, que iremos traçar neste artigo. $O$ foco principal será tentar encontrar uma "genealogia" que ligue essas duas imagens. Parafraseando W.J.T. Mitchell, o que essas duas imagens realmente querem? Será que elas querem a mesma coisa? O fato delas serem bastante semelhantes é apenas uma coincidência? Ou será que elas realmente possuem discursos parecidos e que cada uma, à sua maneira, estaria contribuindo para uma mudança não apenas de meios, mas da própria cultura? Será que seria uma sobrevivência, no sentido dado pelo historiador da arte Aby Warburg?

\section{Neoconcretismo \& A Língua Apunhalada}

$\mathrm{Na}$ década de 1960, após um aparente esgotamento das correntes construtivistas, alguns artistas plásticos começaram a desenvolver trabalhos experimentais que extrapolavam as categorias tradicionais das artes plásticas, no alargamento de suas fronteiras. A mudança conceitual do que constitui o objeto artístico, a atualização e renovação da chamada belas-artes, de toda a sua história e da herança que as mídias tradicionais traziam acabam também marcando a passagem de uma arte moderna para contemporânea.

\footnotetext{
A arte se ajustou ao enquadramento da história da arte tanto quanto esta se adequou a ela. Hoje poderíamos, portanto em vez do fim, falar de uma perda de enquadramento, que tem como consequência a dissolução da imagem, visto que ela não é mais delimitada pelo seu enquadramento. O discurso do "fim" não significa que "tudo acabou", mas exorta a uma mudança no discurso, já que o objeto mudou e não se ajusta mais aos seus antigos enquadramentos. (Belting, 2012 p.13)
}

Essa "perda de enquadramento", que Hans Belting fala, também se desenvolveu de maneira bastante rica e singular na arte brasileira. Por motivos históricos, não foi pelo esgotamento das correntes construtivas que essa mudança ocorreu em nosso país, pelo contrário, foi por meio dela, principalmente do neoconcretismo, que chegamos à arte contemporânea. Como aponta Ronaldo Brito, esse movimento lançou as bases para o aprofundamento de uma arte geométrica abstrata ao mesmo tempo que proporcionou o alargamento de suas fronteiras, ou como o autor denominou, "o vértice e a ruptura". O vértice seria a continuação do desenvolvimento da arte geométrica abstrata em suportes como a pintura e a escultura, tendo como representantes 
nomes como Amilcar de Castro, Franz Weissmann e Willys de Castro. Já a ruptura está ligada às proposições de Hélio Oiticica, Lygia Clark e Lygia Pape, que buscavam outros suportes e meios para as suas pesquisas artísticas, pois o suporte tradicional do quadro e da escultura já não correspondia mais aos seus anseios.

$\mathrm{Na}$ ala que, conscientemente ou não, operava de modo a romper os postulados construtivistas, ocorria sobretudo uma dramatização do trabalho, uma atuação no sentido de transformar suas funções, sua razão de ser, e que colocava em xeque o estatuto da arte vigente. (Brito, 1985 p.51)

Essa dramatização a que Brito se refere seria a incorporação de outros sentidos, e não apenas o visual, no repertório das artes plásticas. Objetos, performances, filmes, fotografias, instalação e toda uma nova série de proposições foram desenvolvidas por esses artistas que, junto com as novas gerações que surgiam, intensificaram e radicalizaram cada vez mais essas proposições.

Lygia Pape, um dos principais nomes do neoconcretismo, após a dissolução do grupo passa a desenvolver uma série de trabalhos relacionados ao cinema, mais especificamente ao grupo do cinema novo. Ela cria cartazes, identidades visuais e letreiros de filmes clássicos desse movimento ${ }^{3}$. Mais para o final da década de 1960, Pape começa a desenvolver curtas metragem experimentais.

Durante uns quatro anos, voltei-me por completo para cinema e a programação visual de filmes, fazendo cartazes e letreiros de uma série de realizações do cinema novo [...] Jamais considerei ocasional essa passagem da minha atividade em artes plásticas até a atuação na área de cinema; vejo uma lógica interna justificando-a, da gravura ao filme. Na gravura, sempre me interessou a pesquisa do espaço. O que é a xilogravura? Uma superficie preta sobre a qual você dá riscos de luz, vai abrindo nela a luz. O que ocorreu comigo foi ter levado isso a um tal ponto que o espaço da gravura terminou consumido. Cavei e cheguei à luz total, espaço idêntico ao espaço real. [...] Nesse momento, comecei a pesquisar em torno da cor/luz, pintando, de

\footnotetext{
3 Lygia Pape criou diversos cartazes e letreiros de filmes do cinema novo. Destacamos os créditos de Mandacaru Vermelho (1961) dirigido por Nelson Pereira dos Santos, em que a artista imprimiu todos os nomes em papel japonês através da técnica da xilogravura e depois na truca aplicou junto com as imagens iniciais do filme. O produtor e cineasta Zelito Vianna, numa conversa informal com o autor, também revelou que a primeira logomarca da produtora Mapa Filmes (que tinha entre os sócios, além de Zelito, Glauber Rocha, Walter Lima Jr., entre outros) foi feita por Lygia Pape. Ainda não conseguimos localizar essa imagem.
} 
início, placas de vidro que deveriam ser penduradas. Mas nelas havia ainda uma certa opacidade. De repente, descobri que no filme eu poderia manipular e dispor dessa luz impalpável, luz/transparência. Foi então que fiz uma série de poemas, já vindos da fase neoconcreta, em cinema: eu os projetava e tinha luz colorida no espaço. Entrei no campo do cinema pela via da luz. Além do mais, o Livro do Criação, de 1960, e também os livros-poemas anteriores já propunham uma situação de narrativa. (Pape, 2004 p.108)

Com esses trabalhos no cinema, Pape desenvolveu um total conhecimento da indústria cinematográfica e de suas etapas de produção (Parente, 2013 p.48), que são bem diferentes do processo de criação individual das artes plásticas. Como a própria artista comenta no trecho acima, o seu caminho para o cinema, a imagem/luz, não está desassociada com os seus trabalhos anteriores. Faz parte de uma pesquisa ampla que a artista percorre ao longo de sua carreira.

O retorno de Pape ao meio das artes plásticas se dá justamente na exposição "Nova Objetividade Brasileira". Essa exposição não foi apenas um marco na recente história da arte brasileira, como também é considerada como uma tomada de posição dos artistas, escrevendo e produzindo pensamentos e críticas a respeito de suas condições, de seus trabalhos e dos rumos que a arte estava tomando. É curioso que nesse "retorno", a radicalidade das propostas de Pape também muda consideravelmente. Não queremos dizer com isso que seja algo que esteja dissociado de seus trabalhos anteriores. Pelo contrário, dando continuidade à sua poética, incorpora novas situações e propostas e suas obras adquirem novos caminhos. "A partir de 1967, a artista inseriu, em sua produção, ordens, configurações e temas mais anárquicos, sem deixar de tocar nas questões que sempre lhe interessaram." (Pequeno, 2017 p.153). Nessa exposição ela apresentou as Caixas de baratas e a Caixa das formigas, incorporando com bastante desenvoltura e humor outros questionamentos em seus trabalhos, sem abandonar as ideias construtivas.

É nesse contexto que ela cria o poema visual Língua apunhalada. $\mathrm{Na}$ forma como ele é apresentado hoje em dia, em backlight - uma caixa de luz por traz da fotografia -, vai totalmente de encontro à forma como Pape descreve o cinema, no trecho acima, "luz impalpável, luz/transparência", criando quase que um holograma no espaço.

Nesse autorretrato, Pape está com a boca totalmente aberta com a língua para fora, mostrando o "sangue". Mas não vemos a ferida, não sabemos se é um corte que esse líquido está escondendo ou se é algo mais profundo, perto da garganta. Também pela expressão facial não visualizamos nenhuma dor ou incômodo da artista. Pelo contrário, com o 
rosto limpo, sem maquiagem e com olhos bem abertos, a artista até aparenta certa serenidade. Apesar de o título do trabalho sugerir, num primeiro momento, um ato de violência explícito, uma agressão física, não é isso que a imagem demonstra.

Apesar de a imagem aparentar essa contradição, nem tudo o que vemos é o que ela nos mostra. O caminho de leitura que o título nos sugere não corresponde com a imagem no real, mas apenas em um sentido figurado. Como W.J.T. Mitchell aponta:

As imagens são marcadas por todos os estigmas próprios à animação e à personalidade: exibem corpos físicos e virtuais; falam conosco, às vezes literalmente, às vezes figurativamente; ou silenciosamente nos devolvem o olhar através de um abismo não conectado pela linguagem. (Mitchell, 2015 p.67)

Essa personalidade própria da imagem é o que elas nos quer mostrar, seu desejo que nem sempre é visível em um primeiro momento. Temos que investigar, analisar e questionar para tentar conseguir ver.

Buscando o significado de apunhalado no dicionário vemos que existem duas definições para esse adjetivo. A primeira, mais comumente usada é: "ferido ou morto a punhal", o que contradiz a imagem, ou seja nosso desejo de ver algo que não está visível na foto. Já a segunda é: "censurado com veemência; exprobrado". A censura é um ato de extrema violência e agressão, mas que não deixa marcas físicas.

A censura da língua indica alguns caminhos. O primeiro é a censura da fala, da palavra, da linguagem. A perda de um tipo de comunicação e socialização do ser humano. Levando em consideração o ambiente político e social que o país vivia, isso era algo que estava em curso como política de Estado. Nesse sentido, fazer a imagem de uma língua apunhalada, exprobada, é um artifício inteligente de subverter essa proibição e, ao mesmo tempo, denunciá-la. A linguagem verbal é excluída, mas ainda restam outras linguagens, como a visual e a corporal, para se comunicar. A perda de um sentido, de uma linguagem, não significa a perda da ideia, da sua materialização e de seu ato. Prática essa que foi bastante utilizada nesse período, e que poderíamos chamar de "conceitualismo à brasileira", descendente direto das rupturas provocadas pelo neoconcretismo.

Um outro caminho, e que não exclui o primeiro, é a censura da língua, no sentido dela ser o músculo responsável pelo paladar. Esse ato implicaria na exprobração de sentir gosto, algo bastante contraditório. Como é possível, proibir, recriminar, reprovar algum sentimento? Talvez essa seja a ironia que a artista imprimiu em seus trabalhos. 
É desse mesmo ano uma outra obra de Pape que dialoga com essa contradição dos sentidos. A instalação Roda dos Prazeres, consiste formalmente num círculo com 16 potes brancos, e cada um desses recipientes contém um líquido de cor diferente, num total de 4 cores distintas. Um conta-gotas é colocado ao lado de cada pote para o espectador/ participador experimentar o líquido. Segundo Pape: "o olhar é seduzido por uma cor, mas o paladar pode reagir de maneira diferente" (Cypriano, 21/04/2001). De maneira oposta do que as cores sugeriram, num senso comum, o seu gosto é desassociado da emoção que a cor nos transmitiria. O vermelho não é picante, é doce; o amarelo não é salgado, é amargo, e assim por diante.

Em diversas montagens desse trabalho, é colocada ao fundo a foto de um homem com chapéu de palha, interagindo com a obra e pingando em sua língua a cor azul. Um outro registro bastante associado com esse trabalho é o da própria artista numa praia deserta com uma faixa azul sobre a cabeça, segurando os cabelos, interagindo com essa instalação e pingando um líquido vermelho. $O$ enquadramento de ambas as fotos é totalmente diferente de Língua Apunhalada. Os registros da instalação são tirados de perfil, num plano aberto, mostrando o ambiente à sua volta e, principalmente, o gesto de pingar com conta-gotas na língua é registrado. Outra diferença fundamental é que as fotos da instalação são fotos em cor enquanto Língua Apunhalada é em preto e branco.

Apesar das diferenças formais entre as fotografias, as imagens do líquido escorrendo pela língua são bastante próximas e, ao mesmo tempo, apontam caminhos opostos, apesar de serem a mesma língua, a língua da artista, e de serem quase do mesmo momento, A língua apunhalada busca uma agressividade, uma violência; já a língua da instalação, como o próprio nome indica, busca prazer, uma satisfação. Fernanda Pequeno, analisando os trabalhos de Lygia pela via do abjeto e do erotismo em relação, por exemplo, a Georges Battaile, aponta a diferenciação que esses conceitos têm na artista: "numa operação corrosiva da moral e dos bons costumes, por outro lado, Lygia Pape aproximou erotismo e abjeção, ao evidenciar as relações entre ambas as instâncias presentes nas abordagens e nos clichês da mulher e do feminino". E conclui:

Jogando com temas, materiais e formas, os trabalhos de Pape, pelos vieses da abjeção e do erotismo, fizeram uso de assuntos e aspectos não palatáveis, mantendo uma postura curiosa e critica, como mulher e como artista. Nas palavras da própria Pape: "Procuro caminhar pela obscuridade das coisas. O que quero é o outro lado. É ver pelas frestas e fazer descobertas." (Pequeno, 2017 p.156)

Essa fala de Pape, de ver pelas frestas e fazer descobertas, encontra paralelo no que Aby Warburg dizia sobre sua iconologia e sobre o seu 
conceito de sobrevivência, em que para ele era possível ver o anacronismo da imagem.

A imagem não é imitação das coisas, mas o intervalo tornado visível, a linha de fratura entre as coisas. Aby Warburg já dizia que a única iconologia interessante, para ele, era uma "iconologia do intervalo". Isso se deve ao fato de que o lugar da imagem não é determinado de uma vez por todas: seu movimento visa desterritorialização generalizada. A imagem pode ser, ao mesmo tempo, material e psíquica, externa e interna, espacial e linguageira, morfológica e informe, plástica e descontínua [...]. (Didi-Huberman, 2015 p.126)

A imagem pelas frestas, seu intervalo, seria esse paradoxo que a própria língua de Pape nos propõe, uma imagem que, em um primeiro momento, nos indica uma direção, mas ao olharmos atentamente vemos os múltiplos e contraditórios caminhos que ela nos sugere.

Outra característica interessante da imagem do autorretrato de Pape é que, por estar com a boca aberta, seu rosto, que tinha uma forma bem arredondada, adquire uma forma oval, emoldurada por uma mancha preta, densa e contrastada dos seus cabelos. A língua irrompe essa forma e vai para o seu exterior. Essa imagem de quebra, de rompimento, também foi explorada pela artista em outro trabalho do mesmo período: Ovo (1968).

Apesar de Ovo ser um cubo branco, e não oval, ambos os trabalhos apontam para o rompimento da casca, para o nascimento, no sentido de surgimento de algo novo. No caso de Ovo, representado pelo trio do embalo maluco, toda a liberdade em relação ao corpo e aos sentidos. No caso da fotografia, essa língua sem função, que não fala e não sente gosto.

Lygia Pape, participa do movimento do cinema novo em sua fase inicial. Porém, no decorrer da década, mais ao final dos anos de 1960, esse movimento, que surge com grande força e como um modelo de ruptura no modo de como se fazia cinema até então no Brasil (filmes de estúdios mais voltados para as comédias, as famosas chanchadas), acaba indo em outra direção e abandona, até certo ponto, a experimentação inicial. Uma tentativa de formar e atrair espectadores que tivesse, como consequência, a criação de uma indústria nacional forte e de seus sistemas correlatos, produção, distribuição e público consumidor. Não que tenha sido uma atitude homogênea, assimilada por todos os seus autores, e mesmo que para isso, como aponta Fernão Ramos, tenha ido num sentido oposto ao ideal do início do movimento. 
Já em direção ao final da década começa, no entanto, a ficar clara uma diferença na postura de diversos diretores quanto à maneira de se ultrapassar esta posição marginal e se atingir 'os amplos setores da população'. O desenvolvimento desta posição toma uma forma que cada vez mais se desliga do discurso armado em torno da 'dimensão política' da obra para se fixar em termos de 'necessidade econômica' e 'realização pessoal', como justificativa para a busca de um público maior. (Ramos, 1987 p.27)

\section{Cinema Marginal \& Família do Barulho}

No final da década de 1960, um grupo de jovens, alguns ligados à crítica cinematográfica na imprensa, começam a fazer seus próprios filmes, em contraponto a essa tentativa de formatação que o cinema novo estava tomando. Preocupados, mais com a linguagem e com as características estéticas do que com a recepção e a assimilação de suas obras pelo público, assumem um caráter experimental e, consequentemente, marginal. ${ }^{4}$ Glauber Rocha no artigo Udigrudi: uma velha novidade diz que: "Os jovens cineastas Tonacci, Sganzerla, Bressane, Neville e outros de menor talento levantaram-se contra o Cinema Novo, anunciando uma velha novidade: cinema barato, de câmara na mão e ideia na cabeça" (Glauber apud. Ramos, 1987 p.27). O que Glauber aponta é que esse modelo de produção já havia sido feito por ele e por seu grupo em sua fase inicial. Talvez, o que ele não consegue admitir é que não se trata apenas de uma questão de produção, mas de toda uma concepção estética, uma tentativa de mudança de linguagem, principalmente da questão narrativa, um tipo de experimentalismo que não era o mesmo do grupo do Cinema Novo. Talvez essa dificuldade deva-se justamente porque Glauber, apesar de ser muito associado com o Cinema Novo, também produziu obras que iam na mesma direção dos filmes experimentais: Pátio (1959), Câncer (1968/1973) e Di (1977) para citar só alguns exemplos na sua cinematografia.

Esse grupo que surge pós Cinema Novo não era um movimento organizado, com manifestos e orientações claras. Os realizadores se organizam mais por afinidades pessoais e estéticas. Autores de estudos fundamentais sobre esse movimento, por uma questão metodológica e

\footnotetext{
${ }^{4}$ Alguns filmes desse movimento tiveram uma boa receptividade de púbico, principalmente o grupo que se formava em São Paulo ao redor da Boca do Lixo. 0 principal exemplo é do cineasta Rogério Sganrzela com Bandido da Luz Vermelha.
} 
histórica, resolveram datar o período de duração desse movimento, apontando seu início em 1968, enquanto o ano de seu fim varia segundo as análises, algumas indicando o ano de 1973 e outras 1975. Neste artigo, como o foco principal é analisar os pontos de contato entre o cinema marginal e as artes plásticas por meio de duas imagens específicas, não iremos nos deter a essas questões cronológicas.

Algumas denominações para esse conjunto de filmes foram cunhadas: Cinema Marginal, Cinema de Invenção, Udigrudi,etc. Na verdade, todos esses filmes estariam englobados no que é conhecido como cinema experimental, que abarcaria, além dessas obras, filmes de artistas, audiovisuais, vídeos e diversas outras propostas com a imagem em movimento.

Entre as diversas tendencias do cinema experimental no Brasil, sem dúvida a mais marcante e original é a do Cinema Marginal, realizado entre 1967 e 1975, movimento sintonizado com o seu tempo: tropicalismo e contracultura, nouvelle vague e pop art. Trata-se de um cinema de ruptura tanto na forma (superexposição das imagens-clichês) como no conteúdo (crítica dos estereótipos comportamentais). Nele, temas psicossociais como o desespero, a violencia, a escatologia e a carnavalização são gerados por uma espécie de impotencia atávica. Trata-se, em última instância, de um cinema que não se contenta com as representações de verdades vividas, mas faz da experimentação da vida uma imagem capaz de superar os limites da nossa impotencia, de nossa idiotia (o monstro caraiba que nós encarnamos sem perceber). (Parente, 2013 p. 47)

Essa experimentação da vida a qual Parente se refere está associada a todo um contexto internacional de confrontações de cânones que foi bastante marcante nos anos de 1960/1970. Como exemplos no mundo, poderíamos citar maio de 1968 na França, o movimento hippie e a contracultura nos Estados Unidos. No Brasil, a esse movimento se junta a contestação ao regime ditatorial, que havia no país desde 1964, gerando um caráter político mais explícito. Mas a questão do experimentalismo, de certa maneira, já brotava em nosso solo alguns anos antes, com as proposições que os artistas oriundos do movimento neoconcreto faziam.

Essa congruência de arte e vida associada com questões políticas gera o que o autor acima chama de "impotência atávica". Esse impedimento, que era vivenciado no dia a dia, não só por esse grupo, mas também por todos que eram contra o regime ditatorial, aparece nessas obras na questão narrativa. Não digo que ele não tenha sido real, pelo contrário, já citamos acima os exemplos de Pape e de Bressane, e poderíamos elencar muitos outros. O que queremos demonstrar é que, apesar de toda essa "impotência atávica", os artistas e cineastas conseguiram superá-las e realizar suas obras, vencendo todas as dificuldades 
(burocracia, censura governamental, questões financeiras, etc.) e transformá-las quase numa metalinguagem, incluindo sua temática. $\mathrm{O}$ crítico e cineasta Jairo Ferreira em relação ao cinema marginal, ou como ele denominou, cinema de invenção, diz:

O experimental em nosso cinema é a música da mente livre, A iluminação de um novo continente. A música de um novo ser da experimental cinematografia terrestre ou não. Estética visionária. / Cinema: poema. Autor de cinema: poeta. Experimental: profeta. / Experimental: antena. Cinema: a estética da luz. (Ferreira, 1986 p.16)

Essa defesa do experimental que Ferreira faz acima, como ato de liberdade e pensamento para a construção da obra, no caso o filme, vai totalmente de encontro com a proposta de como o experimental estava sendo visto nas artes plásticas brasileiras daquele momento. Por exemplo, o conceito de Mario Pedrosa da arte se transformar em "um exercício experimental de liberdade".

Essa tomada de posição desse grupo de cineastas por um experimentalismo, sem fazer grandes concessões à indústria cinematográfica tradicional, principalmente na questão de uma busca de um circuito exibidor tradicional, acabou gerando uma posição marginalizada. E, nesse sentido, talvez por seus opostos, acaba, mais uma vez, sendo parecido com a posição que o grupo neoconcreto tinha tomado alguns anos antes. O neoconcretismo era quase apolítico buscando desenvolver suas propostas à margem de mercado e da própria transformação econômica que o país passava. "Ocorreu, então, esse paradoxo tão brasileiro e tão próprio do subdesenvolvimento: uma vanguarda construtiva que não se guiava diretamente por nenhum plano de transformação social e que operava de certo modo quase marginal." (Brito, 2006 p. 77). Já o Cinema Marginal era político e estava inserido num contexto mais complexo de produção, por conta das características intrínsecas do cinema. Mas rejeitando as posições dominantes e propondo uma nova abordagem da linguagem, via o experimental, os colocava à margem da indústria de cinema tradicional.

Julio Bressane, um dos principais nomes desse movimento, tem sua estreia em um curta-metragem sobre uma jovem cantora que começava a despontar na cena da música brasileira. Bethânia bem de perto: $A$ propósito de um show (1966) é um documentário codirigido com Eduardo Escorel, que mostra o ambiente que precedia o show dessa nova cantora brasileira que, alguns anos mais tarde, junto com outros cantores, cantoras e poetas, seria a base do movimento tropicalista na música. O documentário apresenta algumas características do cinema direto e retrata o início de uma cena experimental, ainda sem o aparato 
do showbiz. Todavia, é com os longas-metragens, Cara a Cara (1967), Matou a família e foi ao cinema (1969) e O Anjo Nasceu (1969) que Bressane desenvolve as bases experimentais que marcariam a sua cinematografia.

No ano de 1970, Julio Bressane, junto com Rogério Sganzerla e a atriz Helena Ignez, fundou uma produtora de cinema, que será um marco para o movimento, chamada Bel-Air. "Não há acordo sobre o tempo de vida exato de Belair. Sganzerla relatou em uma entrevista de 1990 que a empresa existiu de março a setembro. Aponto, no entanto, a tese do crítico de cinema Jairo Ferreira, que afirma que Belair durou de janeiro a março" (Elduque, 2019 p.148/149). Apesar de seu tempo de duração não ser preciso, é consenso que foi bem curto, meses apenas, mas que, mesmo assim, conseguiu realizar um total de seis filmes (Copacabana mon amour, Sem essa aranha e Carnaval no Mangue foram dirigidos por Rogério Sganzerla. Família do Barulho, Cuidado Madame e O horrível Barrão Olavo foram dirigidos por Julio Bressane). Em um esquema de produção cooperativa, Família do Barulho é o primeiro filme da Bel-Air. Sua filmagem durou apenas quatro dias e sua montagem foi realizada no mesmo mês. Algo bastante incomum para a indústria do cinema.

A sinopse do filme pode ser descrita da seguinte maneira:

Uma família disfuncional, composta por uma prostituta e dois gays, um forte e o outro frágil e estúpido, que vive uma vida rotineira no Rio de Janeiro. Quando a vagabunda ameaça os outros dois de parar de apoiá-los, eles decidem encontrar uma odalisca como alternativa para manter a vida fácil. (IMDB)

Até certo ponto ela é verdadeira, numa tentativa de resumir o filme pela questão narrativa, como geralmente são as sinopses. Mas, mesmo por essa via, temos que lembrar que os filmes da Bel-Air são caracterizados por "sua estrutura narrativa frouxa que é frequentemente obscurecida por performances carnavalescas ou dissolvida por rupturas narrativas" (Elduque, 2019 p.149). Pela profusão de acontecimentos e pelas potências das imagens e das ações propostas, que fogem desse roteiro, 0 filme é algo maior, que o resumo não é capaz de abranger. Como disse o poeta Torquato Neto, no artigo A Família do Barulho é da Pesada: "Cada plano existe só e depois que não acaba. Toda a situação é autônoma montagem somassequente de planos". Ou seja, cada cena em sua questão narrativa e estética se desenvolve nela mesma. Mas como essas cenas fazem parte de um filme, um conjunto de cenas, elas também acabam se conectando e ganhando outros significados. Como nos lembra Mondzain, "A força da imagem provém do desejo de ver, a do visível da sua capacidade de ocultar, de construir a distância entre o dado a ver e o objeto do desejo. Sem desejo de ver não há imagem, 
mesmo se o objeto deste desejo não é senão o próprio olhar." (Mondzain, 2009 p. 31).

No caso da imagem apontada no início do artigo, da atriz Helena lgnez vomitando sangue, ela surge no final do filme após outros dois planos dos atores Kleber Santos e Guará Rodrigues, também em situações de close de seus rostos, encarando a câmera, quase sem piscar. Santos é o primeiro que aparece e tem embaixo de seu olho esquerdo, uma mancha escura que se assemelha a uma gota, talvez um choro de sangue. Guará aparece em seguida, de cara limpa, e encara a câmera por alguns segundos, mas interrompe esse ato colocando suas mãos sobre os olhos para, em seguida, abaixar a cabeça como se estivesse escondendo o choro. Por último aparece a imagem de Helena Ignez encarando a câmera de frente. Essas tomadas, do ator ou da atriz olhando a câmera fixamente de frente em um plano fechado, são bastante incomuns nos filmes tradicionais. Elas nos lembram mais uma situação de repressão, as famosas fotografias policiais feitas quando alguém é detido.

Bressane, no filme, utiliza bastante esse recurso da fotografia. Tanto a fotografia em si, com imagens de família aparentemente descontextualizada do núcleo dramático do filme, quanto cenas filmadas estaticamente e posadas dos atores, imitando a linguagem fotográfica. Essas imagens irrompem as cenas do filme, sem relação direta com a narrativa.

No caso da imagem de Helena Ignez, sem levar em consideração que se trata de um frame de um filme, ou seja, que sabemos de antemão o processo que levou até aquele determinado instante, mas apenas olhando para a imagem estática, sua fisionomia, diferentemente do trabalho de Lygia, aparenta um mal-estar. Esse mal-estar pode ser exemplificado pela maquiagem bem escura em volta de seus olhos. Também a mancha que cobre seu queixo nos lembra uma língua, mas a forma de sua boca não condiz com a expressão de quando a colocamos para fora. O estranhamento, que essas zonas escuras em contrataste com a pele branca da atriz e também com seu cabelo despenteado nos passam, é a ideia de que algo está errado. Não sabemos se é externo, como uma apunhalada, ou interno, como uma hemorragia.

\section{As línguas de Lygia Pape e Helena Ignez}

Será que existe alguma ligação entre as artes plásticas e o cinema nesse período? Será que são apenas coincidências as semelhanças das duas imagens? Ou será que existe uma genealogia, uma sobrevivência da 
imagem que as liguem? Nos diversos estudos e artigos em que essas obras são analisadas, elas geralmente são contextualizadas apenas em seus próprios meios e ainda não tinham sido colocadas frente à frente. Se voltarmos para uma crítica que foi desenvolvida no calor dos acontecimentos e que não foi realizada por acadêmicos, mas por poetas, artistas plásticos e por toda uma série de pessoas que não estavam apenas analisando, mas também construindo outras obras artísticas, encontraremos algumas ideias bem interessantes, que não encontram um desenvolvimento posterior. Talvez isso tenha acontecido pela forma de seus textos, que em muitos momentos são bastante confusos e apresentam uma linguagem coloquial característica da época.

O fato da imagem de Helena Ignez ter sido publicada na revista tropicalista Navelouca, como homenagem a Julio Bressane, aponta um caminho. Essa publicação única, que tinha como editores Torquato Neto e Wally Salomão, pretendia fazer um panorama do experimental nas artes. $\mathrm{O}$ fato da revista prestar essa homenagem mostra que o trabalho de Bressane era visto como uma contribuição importante para experimentalismo, e que os seus editores viam diálogos com os outros trabalhos apresentados na publicação. Também Torquato, em sua coluna, Geléia Geral, no jornal Última Hora, diz que Família do Barulho significava para a carreira de Bressane "um momento completo de soluções de suas primeiras principais preocupações e buscas de um cinema concreto brasileiro." (Neto, 1972, p. 54)

Podemos cotejar esse ponto de vista do poeta tropicalista - o de criação de um cinema concreto brasileiro -, com um trecho da fala do cineasta Cacá Diegues em seu discurso de posse na Academia Brasileira de Letras a respeito do cinema novo: "estou convencido de que o Cinema Novo brasileiro [...] não foi senão a chegada tardia do modernismo ao nosso cinema." (Diegues, 2019). Por essa lógica, segundo a análise de Torquato em relação ao filme de Bressane, e consequentemente ao movimento do cinema marginal, seria esse o fim do modernismo no cinema e a abertura de uma nova etapa. Para ele, que vivenciou o que o construtivismo representou nas artes plásticas e na poesia brasileira após o modernismo, faz sentido a afirmação de um cinema concreto. Mas será que de fato o cinema vai nessa direção? Existe alguma incorporação das ideias do construtivismo via os movimentos concreto e neoconcreto no cinema marginal? Historicamente, uma parcela importante do desenvolvimento da gramática cinematográfica se dá via o construtivismo, mais especificamente o russo, com Serguei Eisenstein, Dziga Vertov, entre outros. 
O poeta concretista e ensaísta Haroldo de Campos, analisando a obra do cineasta e fotógrafo Ivan Cardoso, que fazia parte do ambiente tanto do cinema experimental no Rio de Janeiro quanto do circuito de artes plásticas, disse que: "Pelo açougue, também se chega em Mondrian." (Figueiredo, 2009). Essa frase, com alto grau de humor, aponta para o mesmo caminho da ideia de Torquato. Chegar a Mondrian poderia significar chegar a uma nova concepção visual abstrata, sem diferenciação entre a forma e fundo, que no caso do cinema marginal, poderíamos ver na desconstrução narrativa que esse movimento empregava em suas obras, sem uma diferenciação e cronologia dos planos para a construção narrativa. Mas como Haroldo nos lembra, esse caminho se dá via açougue, ou seja, a carne, o sangue, o abjeto. Essa temática está bastante presente nos filmes do cinema marginal e inclusive está na imagem de Helena Ignez, analisada, no artigo, um vômito de sangue. Então esse caminho que o poeta concretista nos aponta é que pelo escatológico, pelo abjeto em sua temática, mas com um rigor construtivo em sua montagem e linguagem, esses filmes chegam a uma nova concepção visual.

Uma análise mais profunda e mais ampla sobre essa genealogia, entre as artes plásticas e o cinema marginal, ainda merece ser realizada. Esse é um estudo inicial, em que identificamos alguns pontos de contato significativos. Como as duas imagens analisadas no artigo demonstram, essa via do experimental, que se utilizava de meios e temas sem preconceitos, com liberdade de ao mesmo tempo subvertê-los e afirmálos em movimentos contraditórios dentro da própria obra, é uma característica marcante dessas duas línguas. A escolha dos temas, a língua, o sangue, o abjeto, o erotismo, também demonstram que não eram coincidências, mas que faziam parte de um projeto maior que estava em curso nesses dois meios. E por fim, toda essa transformação do objeto artístico, que poderia ser visto sob o aspecto do conceitualismo fazem as ligações dessas imagens.

Para finalizar, cabe ressaltar os diversos trabalhos que na década de 1970 tinham a língua como imagem central, principalmente uma língua feminina. Por exemplo, Anna Maria Maiolino, da qual poderíamos destacar a fotopoemação É o que sobra (1974), em que, com uma tesoura, faz o gesto de cortar a sua língua e o seu nariz. Outra artista que desenvolveu vários trabalhos tendo esse músculo como protagonista é Lenora de Barros. Ao longo de sua carreira, essa imagem é bastante recorrente, destacamos entre sua produção a foto Poema (1978), em que a língua da artista é presa pelas letras da máquina de escrever. A própria Lygia Pape, além dos exemplos já citados, também 
explorou a língua em alguns outros trabalhos como imagem central, como, por exemplo, no filme Eat me: a Gula ou a Luxúria (1976).

\section{Bibliografia}

AGUIAR, Carolina Amaral de. Vídeoarte no MAC-USP: o suporte de ideias dos anos 1970. São Paulo: Universidade de São Paulo, 2007.

AMARAL, Aracy. Expoprojeção 73. São Paulo, 1973.

AMARAL, Aracy \& CRUZ, Roberto Moreira. Expoprojeção: 1973-2013 São Paulo: Sesc Pinheiros, 2013.

BELTING, Hans O fim da história da arte - uma revisão dez anos depois. São Paulo: Cosac Naify, 2012 P.13

BRITO, Ronaldo Neoconcretismo: vértice e ruptura Rio de Janeiro: Funarte, 1985 P.51

. As ideologias construtivas no ambiente cultural brasileiro in: FERREIRA, Glória (org.) Crítica de arte no Brasil: temáticas contemporâneas. Rio de Janeiro: Funarte, 2006.

CANONGIA, Ligia. Quase cinema: cinema de artista no Brasil - anos70/80 Rio de Janeiro: Funarte, 1981.

CARBALLAS, Mónica. Rio experimental: más allá del arte, el poema y la acción. Santander: Fundación Botin, 2010.

Cuando Brasil devoró el cine (1960-1970).

Madrid: Museu Nacional Centro de Arte Reina Sofia, 2011.

CYPRIANO, Fabio. A biblioteca de Lygia Pape. São Paulo: Folha de São Paulo 21/04/2001. Recuperado de (https://www1.folha.uol.com.br/fsp/ilustrad/fq2104200113.htm)

COCCHIARALE, Fernando. Filmes de artistas: Brasil 1965-80. Rio de Janeiro: Contra Capa Livraria / Metropolis Produções Culturais, 2007.

COCCHIARALE, Fernando \& BELLA GEIGER, Anna (org.) Abstracionismo geométrico e informal Rio de Janeiro: Funarte, 1987. 
DIDI-HUBERMAN, Georges Diante do tempo: história da arte $e$ anacronismo das imagens. Belo Horizonte: Editora UFMG, 2015.

DIEGUES, Carlos. Discurso de posse na Academia Brasileiras de Letras. Rio de Janeiro, 2019. (http://www.academia.org.br/academicos/carlosdiegues/discurso-de-posse_)

ELDUQUE, Albert. Between film and photography: the bubble of blood in The Family of Disorder. In: Screen, Volume 60, Issue 1, Spring 2019, Pages 148-159, https://doi.org/10.1093/screen/hjy069

FERREIRA, Glória \& CANONGIA, Ligia. Arte/Cinema: filmes experimentais/filmes de artistas plásticos; anos60/70. Rio de Janeiro: Centro Cultural Banco do Brasil, 1997.

FEREIRA, Jairo. Cinema de invenção. Embrafilme e Editora Max Limonand, São Paulo, 1986.

FIGUEIREDO, Luciano. Waly Salomão Galeria Lurix:Rio de Janeiro, 2009 (http://www.lurixs.com/evento/b-a-b-i-l-a-q-u-e-s)

GULLAR, Ferreira. Teoria do não objeto Gullar, in: COCCHIARALE, Fernando \& BELLA GEIGER, Anna (org.) Abstracionismo geométrico e informal Rio de Janeiro: Funarte, 1987. P.239

IMDB -Sinopse do família do barulho

MITCHELL, W.T.J. O que as imagens realmente querem? In: ALLOA, Emmanuel. Pensar a imagem. Belo Horizonte: Autêntica Editora, 2015.

MONDZAIN, Marie-José. A imagem pode matar? Lisboa: Nova Vega, 2009.

Mostra de Arte Experimental de Filmes Super8, Audio-Visual e VideoTape. Rio de Janeiro: Galerie de La Maison de France, 1975.

NETO, Torquato. Torquato Neto: os últimos dias de paupéria. Rio de Janeiro: Livraria Eldorado Tijuca, 1973.

NETO, Torquato \& SAILORMOON, Waly (org.). Navilouca Rio de Janeiro, 1972.

PAPE, Lygia. Lygia Pape / entrevista a Lúcia Carneiro e lleana Pradilla. Rio de Janeiro: Nova Aguilar, 1998 
Ensaios n.11, 2004.

Dossiê Lygia Pape - Homenagem Rio de Janeiro: Arte \&

PARENTE, André. Cinemáticos: Tendências do Cinema de Artista no Brasil. Rio de Janeiro:+2 Editora, 2013.

PEQUENO, Fernanda. Abjeção e erotismo como procedimentos críticos em trabalhos pós-neoconcretos de Lygia Pape. Rio de Janeiro: Arte \& Ensaios n.33 ano $2017 . \quad$ Recuperado de https://revistas.ufrj.br/index.php/ae/article/view/11086

RAMOS, Fernão. Cinema Marginal (1968-1973): a representação em seu limite. São Paulo: EMBRAFILME / Editora Brasiliense, 1987.

XAVIER, Ismail. Alegorias do subdesenvolvimento: cinema novo, tropicalismo, cinema marginal São Paulo: Cosac Naify, 2012. 